Developmental biochemistry fetus glucose 6-phosphate dehydrogenase phosphoenolpyruvatecarboxykinase pyruvate kinase tyrosine transaminase

\title{
Enzyme Induction in Human Fetal Liver
}

\author{
Lorne Kirby and Peter Hahn ${ }^{[29]}$ \\ Departments of Pediatrics and Obstetrics and Gynecology, University of British Columbia, Vancouver, British Columbia, Canada
}

\section{Extract}

Fetal liver obtained from legal abortions was cultured in vitro. The activities of pyruvate kinase $(\mathrm{PK})$, glucose 6-phosphate dehydrogenase (GPD), phosphoenolpyruvate carboxykinase (PEPK), and tyrosine transaminase (TTA) were determined immediately after abortion and after culturing for $24 \mathrm{hr}$. Changes due to culturing were the following: a loss in protein content $(-45 \%)$, a decrease in PK $(-16 \%)$ and GDP $(-40 \%)$ activities, a rise in PEPK activity $(+180 \%)$ and, a fall in TTA activity $(-10 \%)$ in fetuses younger than 16 weeks and a rise in older fetuses $(+60 \%)$.

Dibutyryl cyclic AMP (DcAMP) added to the cultures for the last $5 \mathrm{hr}$ of incubation raised the activities of PEPK and TTA by $35 \%$ and $50 \%$, respectively. Addition of oleic acid together with DL-carnitine had the same effect on PEPK only $(+35 \%)$. PEPK activity was found to be increased 10 -fold in a 12.5 -week-old fetus, the mother of whom had been receiving prednisolone.

It was also found that TTA and cytoplasmic PEPK activities decrease with increasing fetal age.

\section{Speculation}

Our data indicate that it is possible to induce TTA and PEPK very early in fetal life. It is hence possible that certain drugs and hormones applied to the mother have an effect on liver enzyme systems in the young fetus. It seems important to establish whether such induced changes have a deleterious effect on further fetal development.

\section{Introduction}

It is now well established that some fetal liver enzymes can be induced prematurely by cyclic adenosine monophosphate (oAMP) or by glucagon and epinephrine (both presumably acting by activating adenyl cyclase in the liver) administered either to rat fetuses directly in vivo or added to the medium of fetal liver cultures $[9,22]$. The two enzymes studied most extensively are tyrosine transaminase (EC. 2.6.1.5) and phosphoenolpyruvate carboxykinase (EC. 4.1.1.32).

In contrast to these data in the rat and hepatoma cultures $[4,21]$ only one paper has reported experiments with human fetal liver cultures [18]. All of the agents tested in inducing TTA were ineffective, with the exception of triamcinolone, in a 28-week-old fetus.

This lack of experimental data prompted us to examine human fetal liver cultures in some detail. We considered it important to establish reliable evidence, since, as will also be shown here, the possibility exists that agents administered to the pregnant woman might affect the enzyme pattern of the fetus.

\section{Methods}

\section{Tissue Cultures}

Healthy human fetuses aged 7-21 weeks from legal abortions were used. The conceptional age was esti- 
mated from crown-rump lengths and body weight. Fetal liver and kidney were rapidly removed and weighed. Material to be cultured was placed directly in culture medium at $37^{\circ}$. The tissue was cut into pieces approximately $1.5 \mathrm{~mm} /$ side before "being cultured. Four different media were tested: Hank's balanced salt solution, Hank's balanced salt solution without glucose, Eagle's minimum essential medium with Eagle's balanced salt solution, and Eagle's minimum essential medium with Hank's balanced salt solution [16]. The last mentioned medium was chosen because the $\mathrm{pH}$ was best maintained in this solution. The medium contained $100 \mathrm{U}$ penicillin and $100 \mu \mathrm{g}$ streptomycin $/ \mathrm{ml}$. It was also found necessary to add $70 \mathrm{mg}$ sodium bicarbonate/100 $\mathrm{ml}$ medium in order to maintain the $\mathrm{pH}$ at approximately 7.4 throughout the culture period.

About $150 \mathrm{mg}$ tissues were cultured in sterile, disposable 250-ml tissue cultures flasks [24] containing $2.5 \mathrm{ml}$ medium. The flasks were placed horizontally on their broad side so that tissue pieces were about onethird covered by the medium. Histologic examinations showed liver to be viable after incubation for $24 \mathrm{hr}$. Some deterioration was noted when longer incubation periods were used, and hence in the majority of experiments $19 \mathrm{hr}$ was the chosen time of incubation and the inducers were added for a further $5 \mathrm{hr}$. After $24 \mathrm{hr}$ in culture a hematoxylin-eosin-stained section showed well preserved cells, well defined nuclei and intact cell membranes, but a loss of erythrocytes. After $42 \mathrm{hr}$, widespread autolysis was observed. Many nuclei were pycnotic and many cell membranes had lost their original definite shape. A number of parenchymatous cells, however, still appeared viable. The histologic picture after $36 \mathrm{hr}$ in culture was intermediate between the 24- and 42-hr cultures. The following substances were used, the figures denoting their final concentration in the medium: DcAMP, $9 \times 10^{-4}$; glucagon, 10-4; oleic acid, 10-4; DL-carnitine, $5 \times 10^{-5}$; acetyl CoA, $8 \times 10^{-4}$; acetylcarnitine, $9 \times 10^{-4} \mathrm{M}$.

All the procedures described to this point were performed under sterile conditions. At the end of incubation the $\mathrm{pH}$ of the medium in each flask was determined and the tissue was removed, placed in an icecold beaker, and treated as described under Tissue Preparations.

\section{Microsomal Incubation}

This technique was used for determining TTA levels in microsomal suspensions. Test tubes with the suspensions were placed in a water bath at $37^{\circ}$. At zero time various inducers in the final concentrations mentioned above were added and 45 min later the tubes were placed on ice and frozen for at least $36 \mathrm{hr}$. The TTA activity was then determined.

\section{Tissue Preparations}

Fresh tissue and tissue after culturing was homogenized in the cold in 5 times its volume of $0.15 \mathrm{M} \mathrm{KCl}$ in $0.001 \mathrm{~m}$ EDTA using a glass homogenizer and a Teflon pestle. The homogenate was centrifuged in a refrigerated centrifuge [25] at 106,000 $\times g$ for $40 \mathrm{~min}$ and the supernatant was used for the determination of TTA, PEPK, PK (EC. 2.7.1.40), and GPD (EC. 1.1.1.49). The precipitate was resuspended in the same volume of buffer as the original tissue and the homogenate was spun at $600 \times g$ for $10 \mathrm{~min}$. The pellet was discarded and the supernatant recentrifuged at $8,000 \times g$ for $15 \mathrm{~min}$. The resulting mitochondrial pellet was resuspended in $0.1 \mathrm{ml} / 100 \mathrm{mg}$ original wet weight. The suspension was then frozen and thawed three times and centrifuged at $30,000 \times g$ for $10 \mathrm{~min}$. The supernatant was used for the determination of mitochondrial PEPK.

Microsomes for TTA assays were prepared from fresh tissue homogenates. These were first centrifuged at $10,000 \times g$ for $20 \mathrm{~min}$. The resulting supernatant was then recentrifuged at $106,000 \times g$ for $60 \mathrm{~min}$. The resulting pellet was resuspended in $1 / 5$ the original volume of buffer, and divided into $100-\mu \mathrm{l}$ lots into different test tubes.

\section{Enzyme Assays}

Levels of PK and GPD activity were assayed according to the method of Bucher et al. [3], TTA according to the method of Diamondstone [6], and PEPK according to the method of Ballard and Hanson [2]. The method of Lowry et al. [14] was used for protein determinations [26].

\section{Results}

\section{Enzyme Activities in Human Fetal Liver and Kidney}

Since enzyme activities are expressed per unit of protein content, it was first necessary to determine whether the cell fractions used showed any developmental changes in their content of protein. Fig. 1 shows that only slight changes occur in the protein content of both the $106,000 \times g$ supernatant and the mitochondrial fraction of both liver and kidney between the 7 th and 21 st week gestation. The protein content of liver is considerably higher than that of the kidneys. 


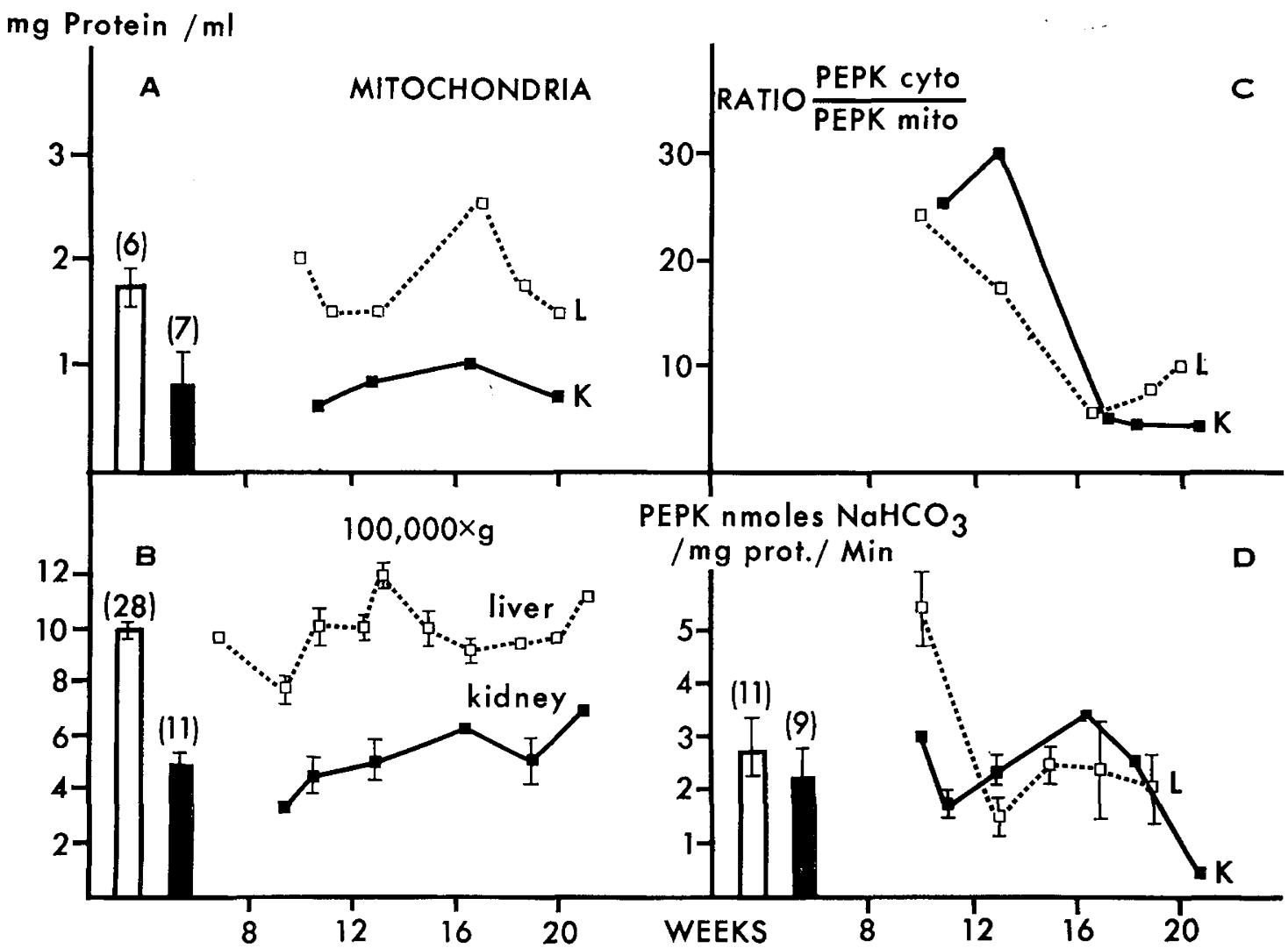

Fig. 1. Changes in the protein (prot.) content of mitochondrial suspensions $(A)$, and of the high speed supernatant $(B)$ obtained from homogenates of liver and kidney tissue and in the activity of phosphoenolpyruvate carboxykinase $(P E P K)(D)$ and the ratio of activity in the cytosol to that in the mitochondria (PEPK cyto/PEPK mito) $(C)$ during fetal development. $L:$ Liver. $K$ : Kidney. The columns show mean values for all fetuses 土se. White: Liver. Black: Kidney. The figures in parentheses show the number of fetuses used. $D:$ High speed supernatant.

PEPK. Activity of this enzyme is low in fetal liver and kidney (Fig. 1). The pH optimum for the enzyme in human fetal liver and also in pig and rat liver is about 7 (Fig. 2). Some PEPK activity was also found in the mitochondrial fractions of both liver and kidney; the ratio of activity in the cytosol to that in the mitochondria decreases with age from about 20 to about 5 , mainly because cytoplasmic activity decreases with age (Fig. 1). In the adult the ratio is 1 [7].

TTA. In contrast to PEPK, TTA activity is about the same in liver and kidney and decreases considerably with age (Fig. 3).

$P K$. The activity of this enzyme in human fetal liver has been described [10]. Values in fetal kidney are about 4 times higher than those in the liver (Fig. 3).

GPD. This activity is also higher in kidney than in liver (Fig. 3).

\section{Tissue Cultures}

Changes in enzyme levels due to incubation of fetal liver have been described only occasionally [20]. With-

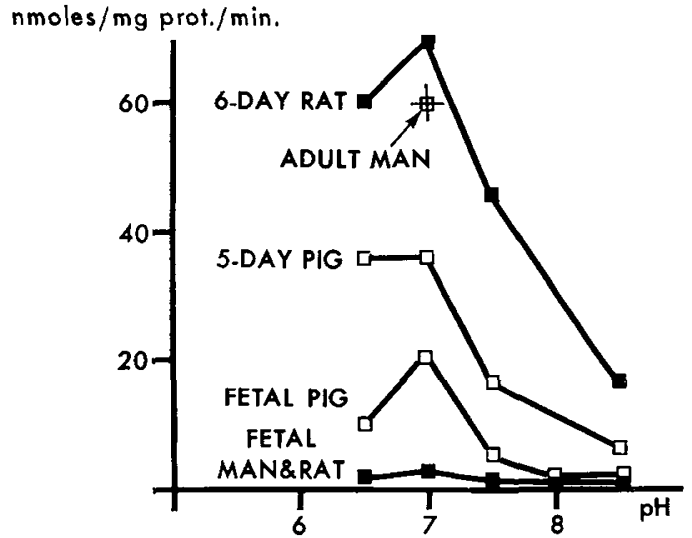

Fig. 2. Phosphoenolpyruvate carboxylase activity of the high speed supernatant of liver tissue from fetal and postnatal mammals of different species in relation to the $\mathrm{pH}$ value of the assay medium. Prot.: Protein.

out a knowledge of such changes, however, it is diffcult to assess the effects of inducers and inhibitors. It is apparent from Fig. 4 that an incubation period of 24 


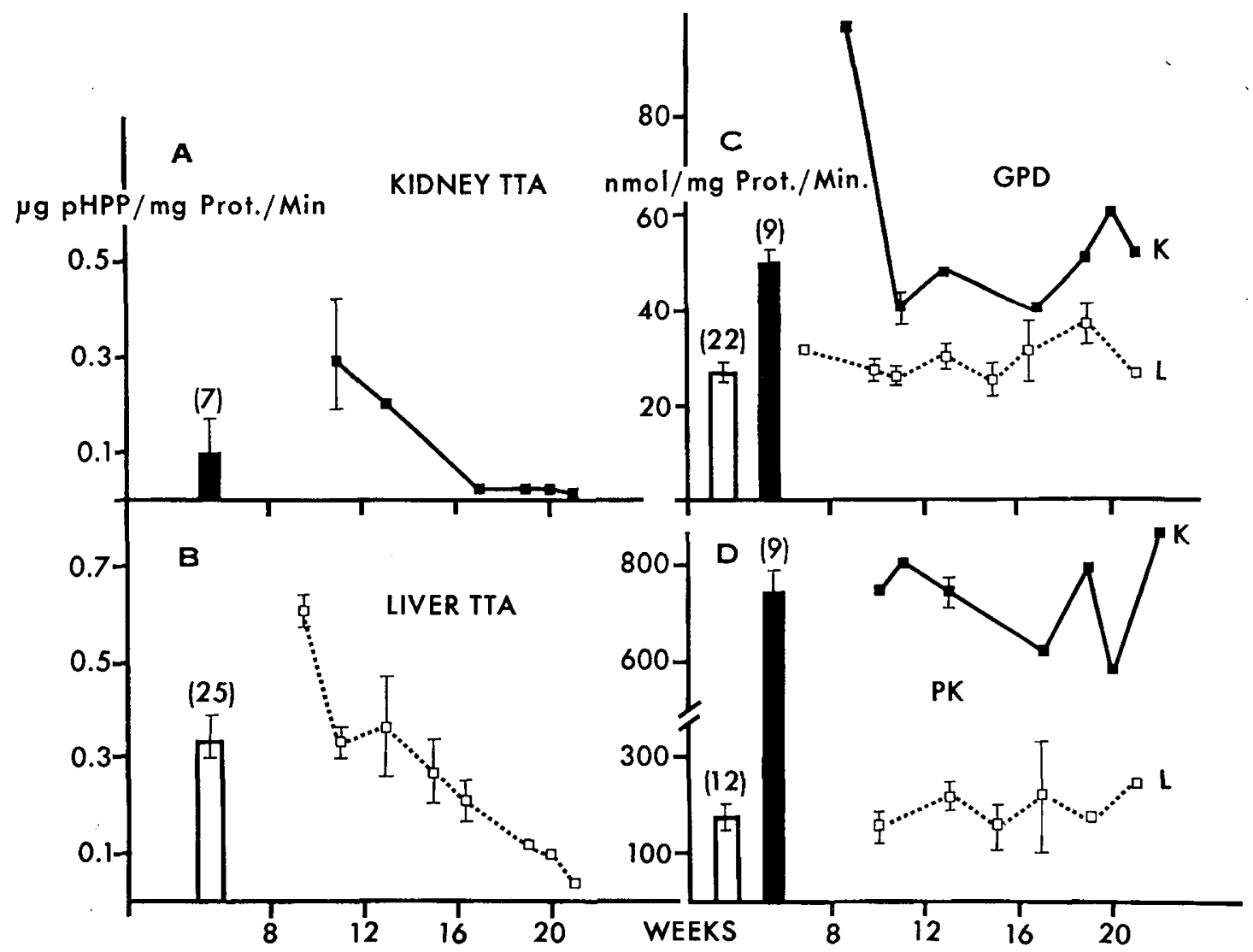

Fig. 3. Changes in the activities of tyrosine transaminase $(T T A)(A, B)$, glucose 6-phosphate dehydrogenase $(G P D)(C)$, and pyruvate kinase $(P K)(D)$ in liver and kidney during fetal development. $p H P P$ : $p$ Hydroxyphenylpyruvic acid. Prot.: protein.

$\mathrm{hr}$ leads to a loss of protein from the cultured material and to a decrease in the activities of PK and GPD. The PEPK activity, on the other hand, is increased at the end of incubation for $24 \mathrm{hr}$. The TTA activity deserves special mention, inasmuch as before the 16th week of gestation culturing leads to a decrease, whereas after that age an increase in activity is noted. The cause of this will be discussed below. In fetal rat liver cultures TTA activity increases during culturing, whereas PEPK activity decreases to very low values [20].

Addition of DcAMP after culture for $19 \mathrm{hr}$ causes an increase in both PEPK and TTA activities $5 \mathrm{hr}$ later at all ages (Fig. 5). This increase is statistically signifcant. The PK and GPD activities are not affected by DcAMP. Addition of DcAMP at the start of culturing had no effect $5 \mathrm{hr}$ later (not shown).

Since oAMP has an immediate effect on both phosphorylase and lipase [19], it was considered possible that its inductive effect on TTA and PEPK activity might be indirect, via released fatty acids. Hence, after culture for $19 \mathrm{hr}$, oleic acid together with DL-carnitine were added to the medium. Five hours later PEPK activity was found to be elevated significantly. No effect on TTA activity was observed (Fig. 5). Acetyl CoA was found to increase PEPK activity by $38 \%$ $(P<0.01$, five fetuses). Neither PK nor GPD activity was affected by this treatment.

It has been reported that TTA is bound to ribosomes (microsomes) in neonatal rat liver and that it is possible to release this bound enzyme by oAMP [5]. Hence, it was thought possible that the rise in TTA activity noted during the culture of human fetal liver tissue might in part be due to release of preformed enzyme. To test for this possibility, isolated microsomes were incubated with DcAMP for $45 \mathrm{~min}$ and the suspensions were later assayed for TTA activity (Fig. 6). Not only DcAMP but also oleic acid and acetyl CoA were responsible for a more than twofold increase in TTA activity, presumably because they led to release of pre-existing enzyme. This was not found in microsomes from an 11-week-old fetus, in which DcAMP caused no release of TTA.

In adult rats in vivo hydrocortisone and other ste- 


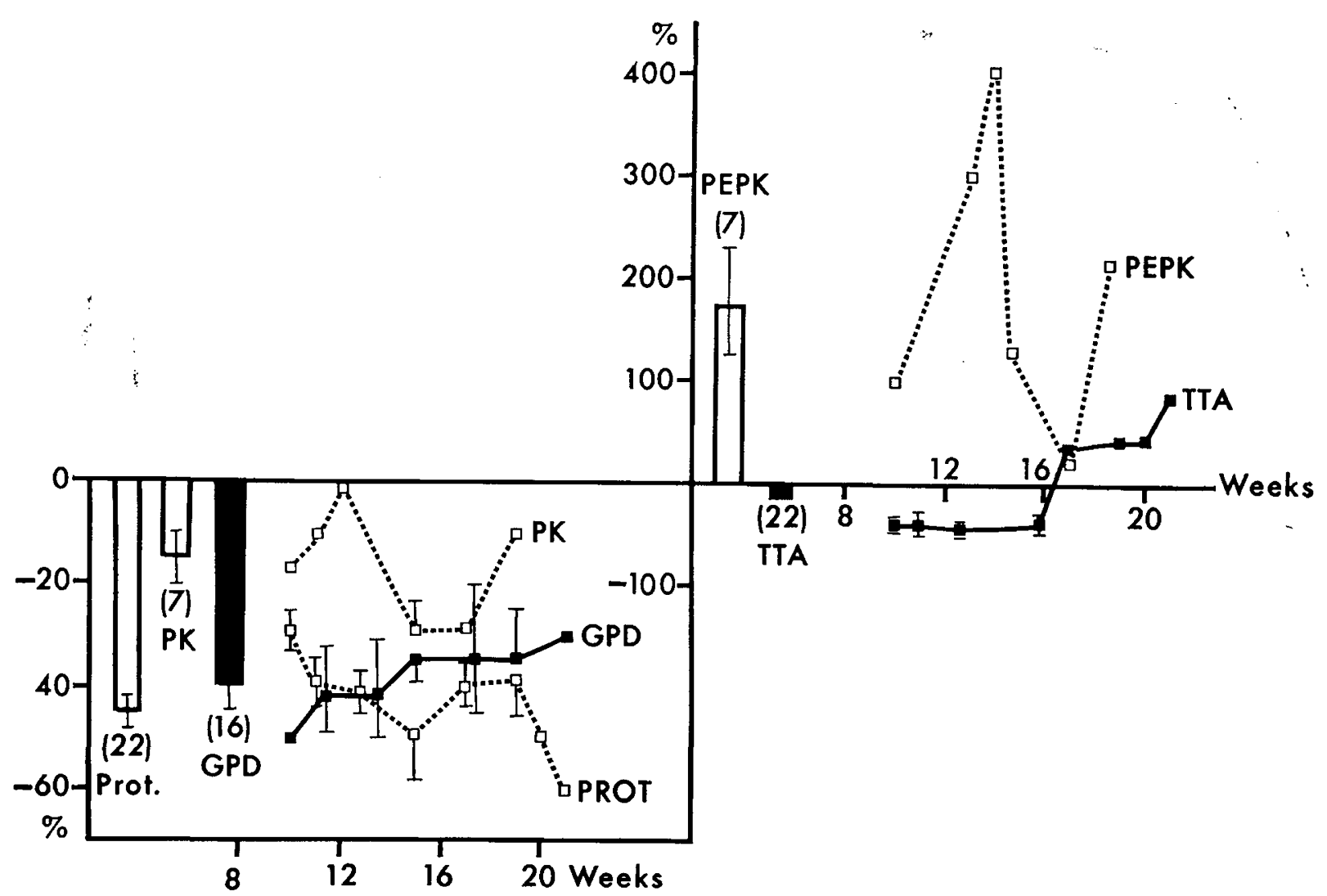

Fig. 4. Changes in the activities of phosphoenolpyruvate carboxykinase (PEPK), tyrosine transaminase (TTA), glucose 6-phosphate dehydrogenase $(G P D)$, and pyruvate kinase $(P K)$ and in protein $(P R O T)$ content of the high speed supernatant after incubation of liver tissue for $24 \mathrm{hr}$ in percentage of the initial values. Fetuses aged 10-21 weeks. The columns designate the mean change for all fetuses $\pm \mathrm{se.} \mathrm{The}$ figures in parentheses show the number of fetuses examined.

roids will induce PEPK and TTA activity. This effect is not observed in fetal animals. Triamcinolone did induce TTA activity in a 28-week-old human fetus [18], but not in younger fetuses. We had occasion to examine the liver of a 12.5-week-old human fetus, the mother of whom had been receiving prednisolone $(20 \mathrm{mg} / 24 \mathrm{hr}$ ) for 8 days before abortion. In this fetal liver PEPK activity was more than 10 -fold higher than in any other fetus ever examined (Table I). The TTA activity was not affected nor was PK activity noticeably different from control fetuses. The GPD activity, however, was about $50 \%$ lower than normally observed.

\section{Discussion}

Our data show unequivocally that DcAMP has an effect in human fetal liver similar to that described in rat fetal liver. We have no direct evidence to indicate whether the rise in TTA and PEPK activity after DcAMP addition is actually induction or only an increase in enzyme activity.
The rise in TTA activity in older human fetuses seen during culturing, on the other hand, is probably partly due to release of preformed enzyme from the microsomes, as described previously in the rat [5]. This release can be effected with DcAMP and also fatty acids and acetyl CoA, indicating a nonspecific effect.

In our opinion, the most important finding is that PEPK activity can be induced not only with DcAMP but also with oleic acid and acetyl CoA. This would seem to indicate that synthesis of a gluconeogenic enzyme is regulated not only by oAMP itself but also by released fatty acids. This has been proposed for the perfused adult rat liver [23], where enzyme induction was not considered. It is noteworthy that oleic acid plus carnitine does not induce PEPK in fetal rat liver [13]. We believe that this is because fetal rat liver possesses very little carnitine acetyl- and carnitine palmitoyltransferase, whereas human fetal liver shows considerable activity of both enzymes [12]. Hence we feel that it is not the oleic acid itself, but the acetyl CoA formed by its oxidation that is decisive. It was shown 


\section{PEPK}

TAT

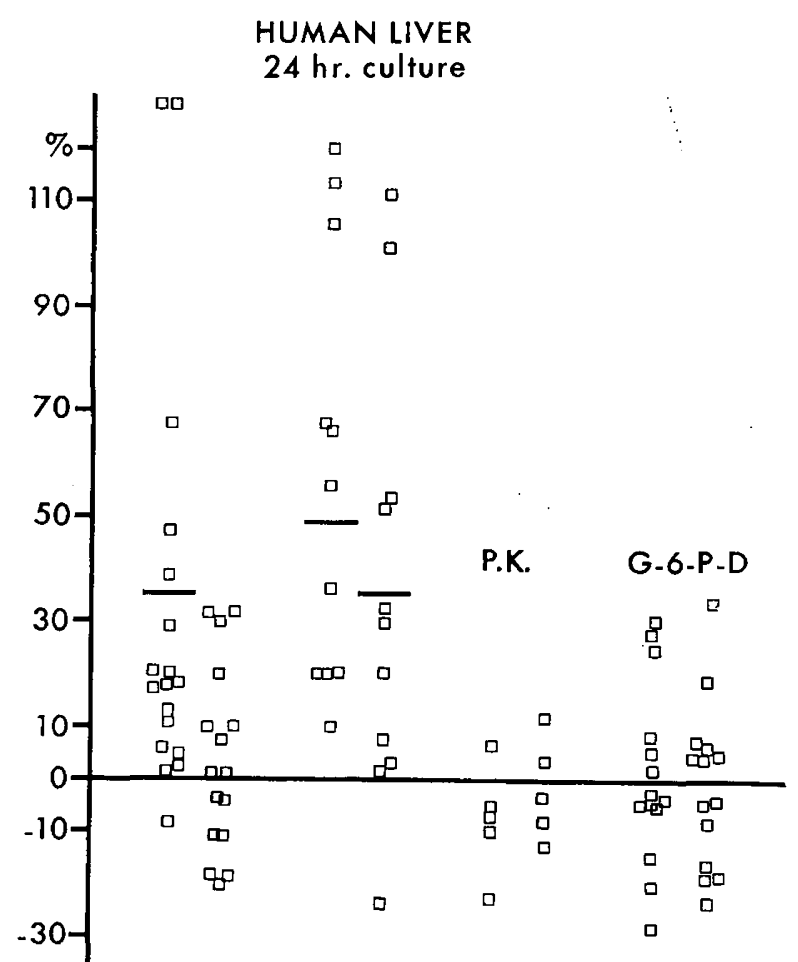

AMP O.A. AMP O.A. AMP O.A. AMP O.A $p<0.01 \quad p<0.01$

Fig. 5. The effect of dibutyryl cyclic adenosine monophosphate $(A M P)$ or oleic acid $(O . A$.) plus carnitine on phosphoenolpyruvate carboxykinase $(P E P K)$, tyrosine transaminase $(T A T)$, pyruvate kinase $(P . K$.$) , and glucose 6-phosphate dehydrogenase (G-6-P-D)$ activities in cultured human fetus liver. Ordinate: Percentage change from control value. After $19 \mathrm{hr}$ of culture dibutyryl cyclic adenosine monophosphate (DcAMP) $\left(9 \times 10^{-4} \mathrm{M}\right.$ final concentration) or oleic acid $\left(10^{-4} \mathrm{M}\right.$ final concentration) plus $\mathrm{DL}$ carnitine $\left(5 \times 10^{-5} \mathrm{M}\right.$ final concentration) was added. Enzymes were assayed after another $5 \mathrm{hr}$ in culture and activities were compared with those found in cultured tissue without any addition. - - means. $\square$ : individual fetuses. The $P$ values refer to the difference between control liver tissue and tissue cultured with DCAMP or fatty acid. In the case of tyrosine transaminase only DcAMP has a significant effect. In the case of PEPK both DCAMP and oleic acid + carnitine significantly elevate enzyme activity. No effect was seen on pyruvate kinase or glucose 6-phosphate dehydrogenase.

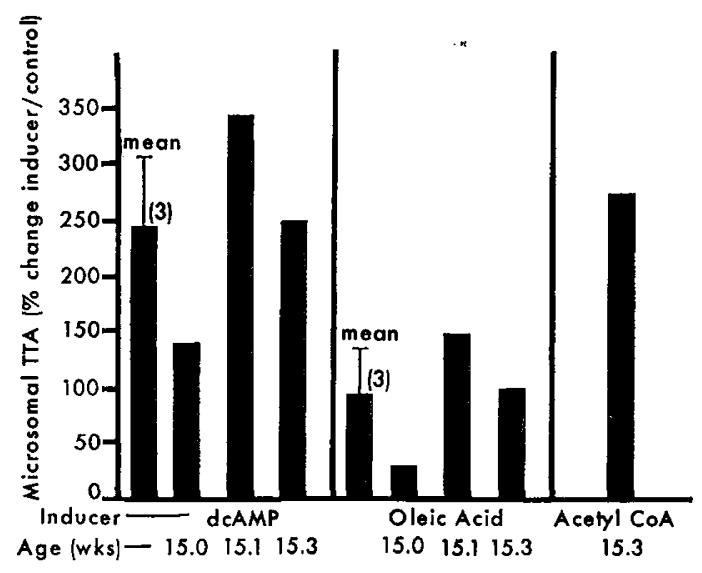

Fig. 6. The effect of dibutyryl cyclic adenosine monophosphate $(D c A M P)$, oleic acid, and acetyl CoA on release of tyrosine transaminase $(T T A)$ from isolated microsomes of fetal human liver. The first four columns show the effect of dibutyryl cyclic adenosine monophosphate, the second four columns, that of oleic acid, and the last column, that of acetyl-CoA. The figures in parentheses show the number of fetuses used. Vertical lines: \pm SE.

previously that human fetal liver can produce ketone bodies from fatty acid [11], but that rat fetal liver does not have a mechanism for fatty acid oxidation. Most probably the enzyme lacking in fetal rat liver is carnitine palmitoyltransferase [1]. This enzyme is present in fetal human liver [13].

Finally, we could also show that administration of hormones to a pregnant woman has a profound effect on liver PEPK activity in her relatively young fetus. It must be assumed that the steroid crossed the placenta [15] and that its prolonged action did induce the enzyme.

\section{Summary}

It has been shown that TTA and PEPK activities of cultured fetal liver tissue can be increased by adding DcAMP to the culture medium for the last $5 \mathrm{hr}$ of a 24-hr period of incubation. Oleic acid + DL-carnitine has the same effect on the latter, but not on the former enzyme.

Table 1 . The effect of injection of prednisolone to a pregnant woman on enzyme activities in the liver of her fetus ${ }^{1}$

\begin{tabular}{lccc}
\hline \multicolumn{1}{c}{ Enzyme } & 12.5 -week-old & Mean for 7-21 weeks & $\begin{array}{c}\text { Fetus from mother } \\
\text { receiving injection }\end{array}$ \\
\hline TTA, $\mu \mathrm{g}$ pHHP/min/mg protein & $0.387 \pm 0.09(4)^{2}$ & $0.347 \pm 0.04(25)$ & 0.56 \\
PEPK, nmoles/min/mg protein & $1.47 \pm 0.4(3)$ & $2.80 \pm 0.5(11)$ & 49.00 \\
PK, nmoles/min/mg protein & $220.0 \pm 15(4)$ & $185.70 \pm 15(12)$ & 154.00 \\
GPD, nmoles/min/mg protein & $30.0 \pm 2.5(3)$ & $27.00 \pm 1.5(22)$ & 19.30 \\
\hline
\end{tabular}

TTA: Tyrosine transaminase. pHHP: $p$-Hydroxyphenylpyruvic acid. PEPK: Phosphoenolpyruvate carboxykinase. PK: Pyruvate kinase. GPD : Glucose 6-phosphate dehydrogenase.

${ }^{2}$ Numbers in parentheses indicate means \pm sE. 
The PEPK activity was found to be elevated 10-fold in the liver of a fetus obtained from a woman treated with prednisolone.

\section{References and Notes}

I. Augenfeld, J., AND Fritz, I. B.: Carnitine palmitoyltransferase activity and fatty acid oxidation by livers from fetal and neonatal rats. Can. J. Biochem., 48: 288 (1970).

2. Ballard, F. J., and Hanson, R. W.: Phosphoenolpyruvate carboxykinase and pyruvate carboxylase in developing rat liver. Biochem. J., 104: 866 (1967).

3. Bucher, T., Luh, W., AND PeTre, D.: In: K. Lang and E. Lehnartz: Handbuch der Physiologischen und Pathologischemischen Analyse. (Springer, Berlin, 1964).

4. Butcher, F. R., Becker, J. E., ANd Potter, V. R.: Induction of tyrosine aminotransferase by dibutyryl cyclic-AMP employing hepatoma cells in tissue culture. Exp. Cell Res., 66: 321 (1971).

5. ChuAh, C.-C., ANd Oliver, I. T.: Role of adenosine cyclic monophosphate in the synthesis of tyrosine aminotransferase in neonatal rat liver. Release of enzyme from membranebound polysomes in vitro. Biochemistry, 10: 2990 (1971).

6. Diamondstone, T. I.: Assay of tyrosine transaminase activity by conversion of $p$-hydroxyphenylpyruvate to $p$-hydroxybenzaldehyde. Anal. Biochem., 16: 395 (1966).

7. Diesterhaft, M., Shrago, E. and Sallach, H. J.: Human adult liver phosphoenolpyruvate carboxykinase; Evidence for a separate mitochondrial and cytosol enzyme. Biochem. Med., 5: 297 (1971).

8. GREengARD, O.: The hormonal regulation of enzymes in prenatal and postnatal rat liver. Biochem. J., 115: 19 (1969).

9. GREengard, O.: The developmental formation of enzymes in rat liver. In: G. Litwack: Biochemical Action of Hormones, Vol. I, p. 53. (Academic Press, New York, 1970).

10. Hahn, P., and Skala, J.: Some enzymes of glucose metabolism in the human fetus. Biol. Neonate, 16: 362 (1970).

11. Hahn, P., and Vavrouskrova, E.: Ketone body production by human fetal liver. Biol. Neonatorum, 7: 348 (1964).

12. Hahn, P., and Skala, J.: Carnitine transferases in human fetal tissue. Biol. Neonate, in press.

13. Kirby, L., and HaHN, P.: Enzyme activities during culturing of fetal rat liver. Can. J. Biochem., in press.
14. Lowry, O. H., Rosebrough, N. J., FArR, A. L., AND Randall, R. J.: Protein measurement with the Folin phenol reagent. J. Biol. Chem., 193: 265 (1951).

15. ORTI, E.: Steroid hormone formation and metabolism. In: U. Stave: Physiology of the Perinatal Period, Vol. 2, p. 909. (Appleton-Century-Crofts, New York, 1970).

16. PAul, J., Cell and Tissue Culture. (E. \& S. Livingstone, London, 1970).

17. Philippidis, H., Hanson, R. W., Reshef, L., Hopgood, M. F., AND Ballaro, F. J.: The initial synthesis of proteins during development. Biochem. J., 126: 1127 (1972).

18. RÄIHÄ, N. C. R., Schwartz, A. L., ANd Lindroos, M. C.: Induction of tyrosine- $\alpha$-ketoglutarate transaminase in fetal rat and fetal human liver in organ culture. Pediat. Res., 5: 70 (1971).

19. Robison, G. A., Butcher, R. W., and Sutherland, E. W.: Cyclic AMP. (Academic Press, New York, 1971).

20. Serent, F., ANd Serent, L. P.: Spontaneous development of tyrosine animotransferase activity in fetal liver cultures. Advan. Enzyme Regul., 8: \$\$ (1970).

21. Wraks, W. D.: Induction of hepatic enzymes by adenosine 3,5-monophosphate in organ culture. J. Biol. Chem., 244: 3941 (1969).

22. Wrcks, W. D.: Regulation of hepatic enzyme synthesis by cyclic AMP. Ann. N. Y. Acad. Sci., 185: 152 (1971).

23. Williamson, J. R., Thurman, R. G., and Browning, E. T.: Studies on the mode of action of glucagon in rat liver, In: P. Foà: The Action of Hormones. (Charles C Thomas, Publisher, Springfield, Ill., 1971).

24. No. 3024, Falcon Plastics, Oxnard, Calif.

25. IEC, Mass.

26. Chemicals were obtained from Sigma Chemical Company, St. Louis, Mo., and Calbiochem, Los Angeles, Calif.

27. Lorne Kirby is a postgraduate student in the Department of Paediatrics, Division of Medical Genetics, Medical Research Council of Canada. Peter Hahn is an Associate of the Medical Research Council of Canada.

28. This work was supported by the Medical Research Council of Canada.

29. Requests for reprints should be addressed to: PETER HAHN, M.D., Department of Obstetrics and Gynecology, University of British Columbia, Canada.

30. Accepted for publication October 12, 1972. 